\title{
SMR을 갖는 소형풍력발전시스템의 센서리스 MPPT제어 \\ Sensorless MPPT Control for a Small-scale Wind Power Generation System with a Switched-mode Rectifier(SMR)
}

\author{
허 성 덕**이 준 민 ${ }^{*}$ 김 영 석 ${ }^{*}$ \\ (Chengde $\mathrm{Xu} \cdot$ Joon-Min Lee $\cdot$ Young-Seok Kim)
}

\begin{abstract}
A small-scale wind power generation system with a switched-mode rectifier(SMR) is proposed. To simplify the converter circuit of the wind power generation system, the synchronous inductors of the permanent magnet synchronous generator(PMSG) replace the inductor for the boost converter. The sensorless maximum power point tracking(MPPT) control is carried out for the wind power generation system with the SMR. The proposed system is verified through the simulations and the experiments.
\end{abstract}

Key Words : Small-scale, Wind power generation system, PMSG, SMR, MPPT, Inverter

\section{1. 서 론}

석유, 석탄 등 화석연료의 사용은 오늘날 지구 온난화, 기 후문제 등 심각한 환경문제와 자원의 고갈 문제를 초래하였 고 이로 인해 신재생에너지에 대한 연구가 많이 진행되고 있다. 신재생에너지의 종류로 풍력, 조류, 태양광 등을 이용 한 발전시스템이 대표적으로 연구되고 있고 그 중에서 풍력 발전에너지는 청정에너지인 바람을 이용하여 발전비용이 저 렴하여 기존 화석연료를 대체할 수 있는 효과적인 에너지원 으로 알려져 있다[1].

현재 풍력발전시스템은 주로 Back-to-back시스템(그림 1)과 $\mathrm{DC}-\mathrm{DC}$ 컨버터 시스템(그림 2)에 대해 연구가 진행되 고 있다[2-3]. Back-to-back 컨버터시스템에서 발전기 측 컨버터에서는 발전기의 속도제어를 통하여 최대 전력점 추 종제어(MPPT) 수행하게 되고 계통측 컨버터에서는 전류제 어를 통하여 계통전압과 전류의 위상을 제어하게 된다. 이 시스템은 제어성능이 좋고 시스템을 대용량으로 할 수 있다 는 장점을 가지고 있다. 그러나 발전기 측에 6 개의 스위치 가 필요하고 복잡한 제어를 요구하는 단점이 있다. 더구나 소형 풍력발전시스템에서 가격적인 부담이 커지게 되어 소 형 시스템에 적용하기에는 적합하지가 않다. DC-DC 컨버터 시스템에서는 주로 boost converter를 사용하고 있고 boost converter의 스위치 제어를 통하여 발전기의 속도를 제어하 게 되고 이로써 MPPT제어를 수행하게 된다. 이 시스템은 많은 수동소자를 필요로 하고 있어 시스템의 부피가 커지고 가격이 상승하게 되는 단점이 있다.

\footnotetext{
$\uparrow$ Corresponding Author : Dept. of Electrical Engineering, Inha University, Korea

E-mail : youngsk@inha.ac.kr

* Dept. of Electrical Engineering, Inha University, Korea Received : October 4, 2013; Accepted : November 17, 2013
}

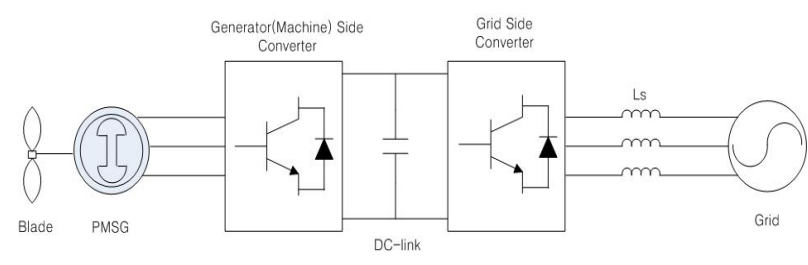

그림 1 Back-to-Back 컨버터를 이용한 풍력발전시스템

Fig. 1 Wind power generation system with back-to-Back converter System

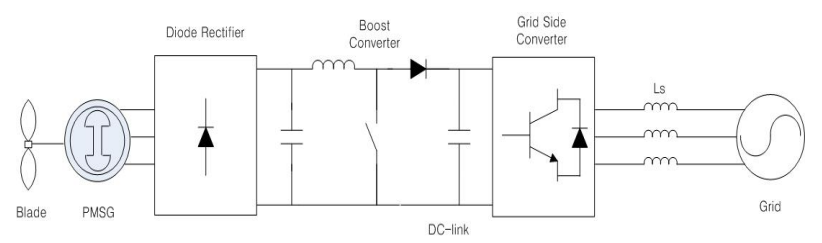

그림 2 Boost 컨버터를 이용한 풍력발전시스템

Fig. 2 Wind power generation system with boost Converter System

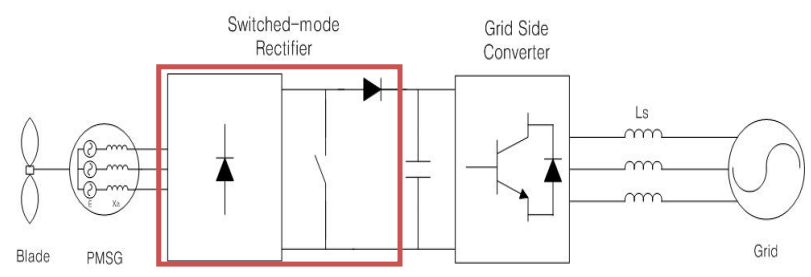

그림 $3 \mathrm{PMSG}$ 와 SMR를 이용한 풍력발전시스템

Fig. 3 Wind power generation system with SMR

본 논문에서는 영구자석동기발전기의 동기 임피던스를 이 용하여 삼상 부스터형 SMR시스템을 제안하고 있다. (그림 3) 제안한 시스템의 구성은 영구자석동기발전기, Switchedmode Rectifier(SMR), 계통 연계 형 삼상 인버터로 이루어 
져있다. 영구자석동기발전기의 동기임피던스는 기존의 boost converter 시스템에서 인덕터를 대체할 수 있어 부스트 효 과를 낼 수 있다. 본 시스템은 SMR회로를 사용하여 기존의 부스트 회로와 같은 동작을 수행할 수 있고 수동소자의 제 거로 시스템의 가격과 부피를 줄일 수 있다. 또한 센서리스 $\mathrm{MPPT}$ 제어를 사용함으로써 센서의 가격적인 부담을 줄일 수 있어 경제적이고 효율적인 시스템이다.

\section{2. 본 론}

\section{1 풍력 터빈 모델}

풍력에너지로부터 블레이드에서 얻을 수 있는 전력 $P_{\text {blade }}$ 는 상수와 풍속 그리고 블레이드의 효율계수로 정의할 수 있다.

$$
P_{\text {blade }}=\frac{1}{2} \rho A C_{p}(\lambda, \beta) v_{\text {wind }}^{3}
$$

여기서 효율계수인 $C_{p}$ 는 주속비(TSR) $\lambda$ 와 피치각 $\beta$ 의 함수이고 주속비는 식 (2)와 같이 정의된다.

$$
\lambda=\frac{R \cdot \omega_{\text {blade }}}{v_{\text {wind }}}
$$

식 (1)(2)에서 $A$ 는 블레이드의 회전 단면적 $\left[m^{2}\right], \rho$ 는 공기의 밀도 $\left(1.225\left[\mathrm{~kg} / \mathrm{m}^{3}\right]\right), \quad C_{p}(\lambda, \beta)$ 는 출력계수, $v_{w i n d}$ 는 풍속 $[\mathrm{m} / \mathrm{sec}], \quad R$ 은 터빈의 반지름 $[m], \quad \omega_{b l a d e}$ 는 발전기의 회전속도 $[\mathrm{rpm}]$ 이다. 파워계수 $C_{p}(\lambda, \beta)$ 는 터빈이 받아들이 는 에너지 대 풍력에너지의 비율을 의미한다. $C_{p}(\lambda, \beta)$ 의 값은 주속비 $\lambda$ 의 함수식으로 식(3)과 같이 근사화 하였다.

$$
C_{p}(\lambda, \beta)=C_{1}\left(\frac{C_{2}}{\lambda_{i}}-C_{3} \beta-C_{4}\right) e^{-\frac{C_{5}}{\lambda_{i}}}+C_{6} \lambda
$$

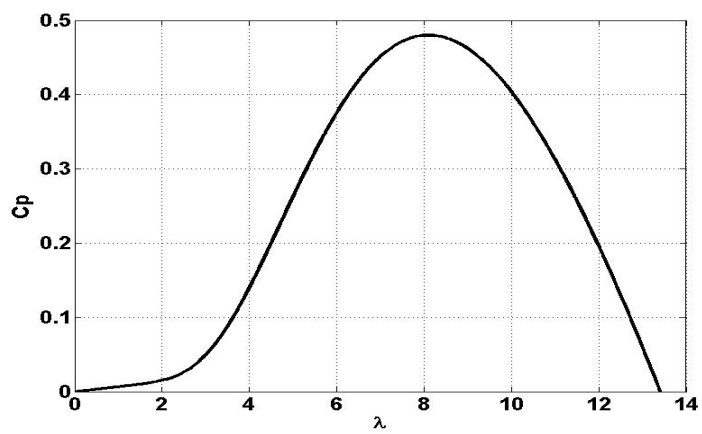

그림 4 효율계수곡선

Fig. 4 the power coefficient curve

$$
\frac{1}{\lambda_{i}}=\frac{1}{\lambda-0.08 \beta}-\frac{0.035}{\beta^{3}+1}
$$

여기서

$$
C_{1}=0.5176, C_{2}=116, C_{3}=0.4, \quad C_{4}=5, \quad C_{5}=21,
$$

$C_{6}=0.0068$ 이며 피치각 제어는 고려하지 않으므로 $\beta=0$ 으로 설정하였다.

$\lambda-C_{p}$ 의 관계 그래프를 MATLAB을 이용하여 그림 4 와 같이 나타내었다.

주속비와 효율계수의 관계곡선에 의하면 효율계수가 0.48 인 최대가 되는 주속비가 존재한다는 것을 알 수 있다. 효율계수가 최대를 가질 때 발전기는 최대의 전력을 낼 수 있다.

\section{2 풍력 터빈 특성}

풍력발전시스템에서 바람의 속도에 대한 풍력터빈의 특 성에 의하면 특정한 바람의 세기에서 출력전력과 회전속도 사이에는 그림 5 와 같은 관계를 가지게 된다. 특정된 바람 의 세기에서 특정된 터빈의 특성곡선이 나오게 되고 최대의 전력점이 존재하게 된다. 이 전력점에서 발전기를 회전하게 하면 발전기는 최대의 전력을 얻을 수 있게 된다.

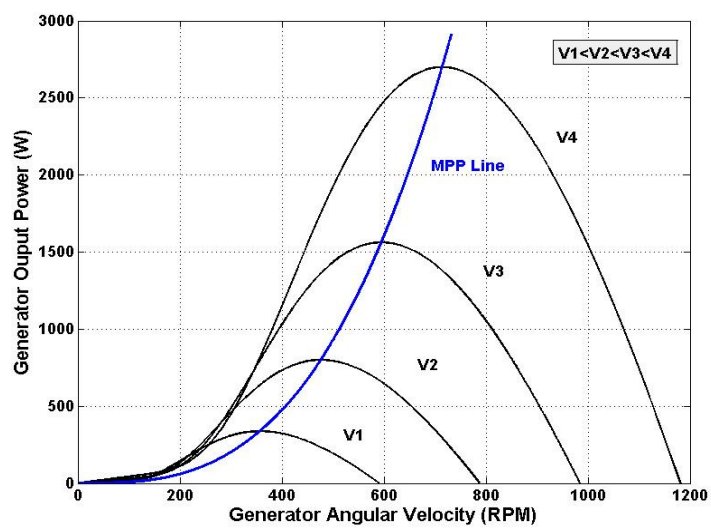

그림 5 풍력터빈의 특성곡선

Fig. 5 Characteristic curves of the wind turbine

\subsection{Switched-mode Rectifier}

Switched-mode rectifier(SMR)(그림 6) 회로는 삼상 다이 오드 정류기와 스위치 및 싱글 다이오드로 이루어져있다. 영구자석발전기의 고정자 동기임피던스와 SMR회로의 삼상 부스트 정류기의 형태를 지니게 되고 기존의 부스트 컨버터 시스템이랑 비슷한 동작을 하게 된다. $\mathrm{SMR}$ 회로는 기존의 부스트 컨버터 회로보다 적은 수동소자를 가지고 같은 동작 을 수행함으로써 경제적인 면에서 이득을 볼 수 있는 게 장 점이다.

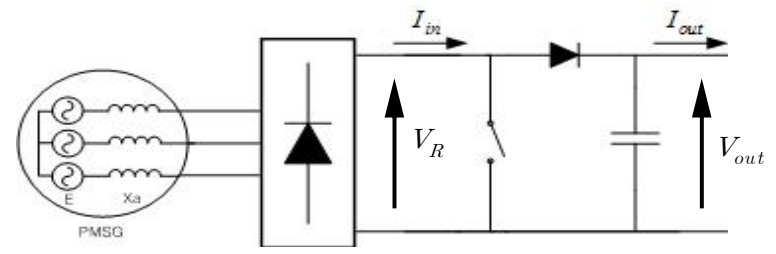

그림 $6 \mathrm{SMR}$ 회로

Fig. 6 SMR circuit 
삼상 정류기 출력전압, 전류와 $\mathrm{SMR}$ 출력전압 전류사이에 는 아래 식과 같은 관계를 얻을 수 있다. (그림 7) 발전기의 리액턴스 성분과 스위치에 의하여 전압은 승압되게 된다[4].

$$
\begin{aligned}
V_{R} & =(1-D) V_{\text {out }} \\
I_{\text {out }} & =(1-D) I_{\text {in }}
\end{aligned}
$$

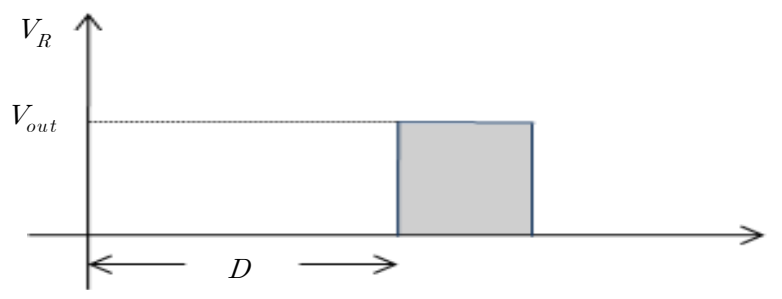

그림 7 정류기 출력전압

Fig. 7 The output voltage of the rectifier

다음절에서 나오게 되는 인버터에서 DC-link의 전압을 정전압제어를 하게 된다. SMR에서 스위치에 의해서 부스팅 은 되지만 인버터에서는 정전압 제어를 하게 되어 결론적으 로는 $\mathrm{SMR}$ 의 스위칭에 의해서 정류기의 출력전압 $V_{R}$ 이 변 하게 된다. 식(5)에 의하면 듀티비가 커질수록 정류기 출력 전압 $V_{R}$ 은 작아지게 되고 듀티비가 작아질수록 $V_{R}$ 은 커지게 된다.

\section{4 계통연계 형 삼상 인버터}

삼상 인버터 모델링을 하기 위하여 계통 삼상 전압, 전류 를 3상 2상 좌표변환을 하여 제어하게 된다. 저항과 인덕터 필터에 의한 전압방정식을 세우게 되면 식(7)과 같이 나타 낼 수 있다. 좌표변환을 통하여 식(7)에는 역기전력 전향 보 상성분이 나타나게 되고 이는 보상함으로써 제거할 수 있다 [5].

$$
\left[\begin{array}{l}
V_{d} \\
V_{q}
\end{array}\right]=\left[\begin{array}{cc}
R+p L & -\omega L \\
\omega L & R+p L
\end{array}\right]\left[\begin{array}{c}
I_{d} \\
I_{q}
\end{array}\right]+E\left[\begin{array}{l}
1 \\
0
\end{array}\right]
$$

DC-link 캐패시터에서 전력의 관계식을 식 (8)와 같이 얻 어낼 수 있다.

$$
C V_{d c} \frac{d V_{d c}}{d t}=P_{i n}-P_{o u t}=P_{i n}-\frac{3}{2} e_{d} i_{d}
$$

PI제어기 (식(9))로 전압제어기 구성가능하고 Closed-loop 전달함수는 식(10)과 같이 표현할 수 있고 이로써 정전압제 어기를 구성할 수 있다.

$$
\begin{aligned}
& i_{d}^{*}=K_{p}\left(V_{d c}^{*}-V_{d c}\right)+K_{i} \int\left(V_{d c}^{*}-V_{d c}\right)+P_{i n} / \frac{3}{2} e_{d} \\
& \frac{V_{d c}}{V_{d c}^{*}}=\frac{\frac{3}{2} e_{d} K_{i}+\frac{3}{2} e_{d} K_{p} s}{C V_{d c} s^{2}+\frac{3}{2} e_{d} K_{p}+\frac{3}{2} e_{d} K_{i}}
\end{aligned}
$$

정전압제어기와 전류제어기를 결합하여 인버터 제어블록 도를 구성할 수 있고 그 블록 구성은 그림 8 과 같이 나타낼 수 있다.

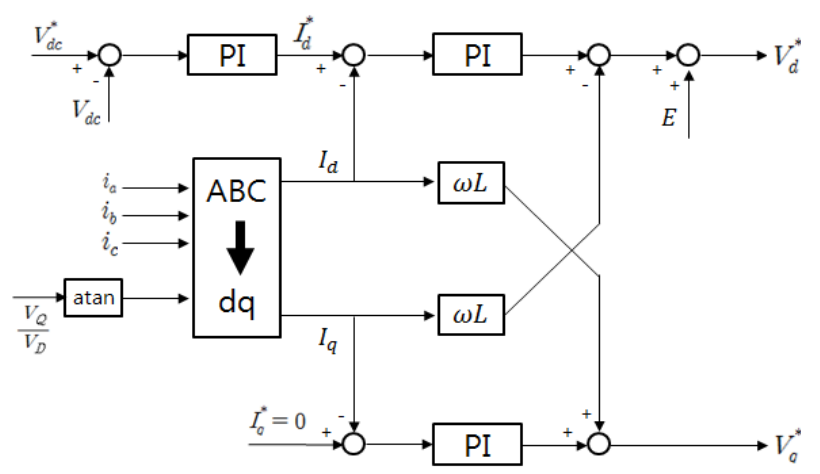

그림 8 인버터 제어블록도

Fig. 8 Block diagram of the inverter control system

인버터 제어를 통하여 DC-link 전압은 정전압제어를 하 게 되고 계통 전압 전류는 단위 역률로 제어하게 된다.

\section{5 센서리스 MPPT제어}

본 시스템에서는 기계적인 속도 센서없이 SMR회로의 듀 티비를 가변하여 최대의 전력을 추종하는 MPPT제어 방법 을 사용하였다. 듀티비에 의하여 최대의 전력을 추종하기 위해서는 전력과 듀티비 사이의 상관관계가 필요하다. 터빈 의 특성곡선을 바탕으로 연쇄법칙을 사용하여 듀티비와 전 력사이의 관계를 그림 9 와 같이 얻을 수 있다[6].

$$
\frac{d P}{d D}=-\frac{d P}{d \omega}=0
$$

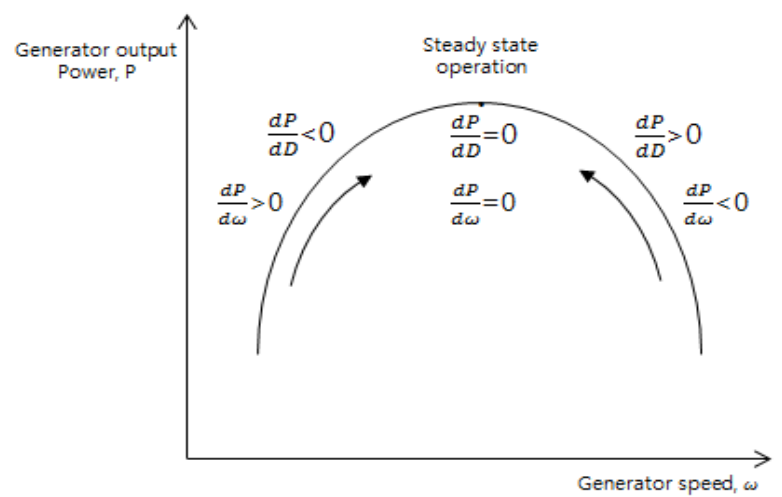

그림 $9 \mathrm{MPP}$ tracking 과정

Fig. 9 MPP tracking process

듀티비와 전력사이의 관계로부터 그림 10 과 같은 MPPT 알고리즘을 작성할 수 있다.

(1) 시작할 때 초기 듀티비를 설정하고 듀티 단계를 인가 한다.

(2) 측정해 온 전압전류로 전력을 계산한다. 
(3) 이전 전력 값과 비교를 하여 전력이 상승하면 원래 동작을 그대로 수행하고 아니면 역으로 동작을 하게 한다.

(4) (2),(3),(4)번을 반복한다.

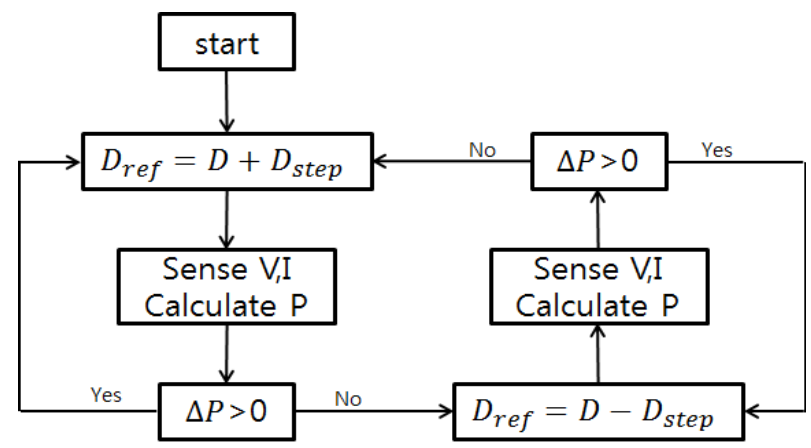

그림 $10 \mathrm{MPPT}$ 제어 알고리즘

Fig. 10 MPPT control algorithm

전력 계산에 필요한 전압과 전류는 인버터에서 좌표변환 을 통한 전압 전류로 계산을 한 값이다. 알고리즘은 전력의 변화를 통해서 전력이 커지면 원래의 동작을 그대로 수행하 고 아니면 동작을 역으로 수행하여 최대의 전력점을 추종하 게 되고 이로써 MPPT제어를 할 수 있다.

\section{6 시뮬레이션}

제안한 풍려발전시스템을 검증하기 위하여 PSIM 시뮬레 이터를 이용하여 시뮬레이션을 수행하였다. 시뮬레이션은 실제 실험정수를 기초로 하여 시뮬레이션을 하였고 시뮬레 이션 정수는 표 1 에 보인바와 같다.

표 1 풍력발전시스템 변수

Table 1 Parameters of the wind generation system

\begin{tabular}{|l|ll|}
\hline Generator rated power & $3.7 \mathrm{k}$ & $\mathrm{W}$ \\
\hline rated voltage & 380 & $\mathrm{~V}$ \\
\hline rated current & 7.7 & $\mathrm{~A}$ \\
\hline stator registance & 0.324 & $\Omega$ \\
\hline d-axis inductance & 10.1 & $\mathrm{mH}$ \\
\hline q-axis inductance & 27.37 & $\mathrm{mH}$ \\
\hline back-emf constant & 159.8 & $\mathrm{Vpk} / \mathrm{krpm}$ \\
\hline rated speed & 1800 & $\mathrm{rpm}$ \\
\hline pole pair & 4 & \\
\hline DC-link capacitor & 8200 & $\mathrm{uF}$ \\
\hline Grid filter inductance & 3 & $\mathrm{mH}$ \\
\hline Grid filter resistance & 0.05 & $\Omega$ \\
\hline Grid filter capacitance & 10 & $\mathrm{uF}$ \\
\hline Grid voltage & 60 & $\mathrm{~V}$ \\
\hline
\end{tabular}

그림 11은 MPPT 제어를 통하여 효율계수가 최대의 값인 0.48 을 추종하는 것을 보여주고 있고 최대의 효율계수를 갖 게하는 주속비의 값은 그림 12 에서 8 인 값을 추종하는 것을 볼 수 있다.

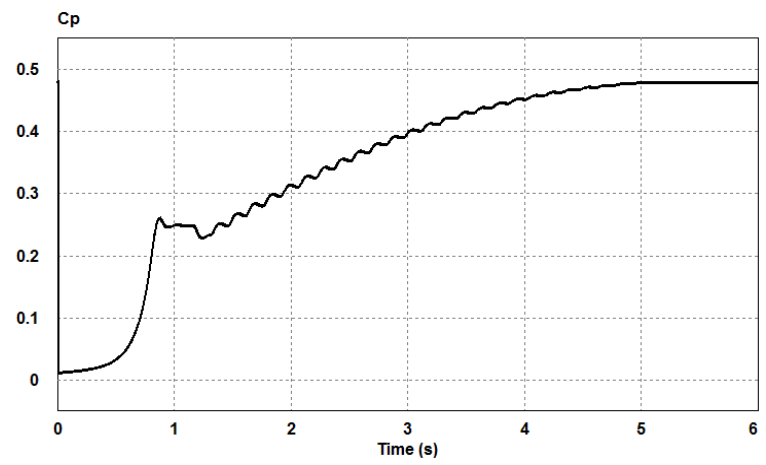

그림 11 효율계수 $\mathrm{Cp}$

Fig. 11 Power efficient $\mathrm{Cp}$

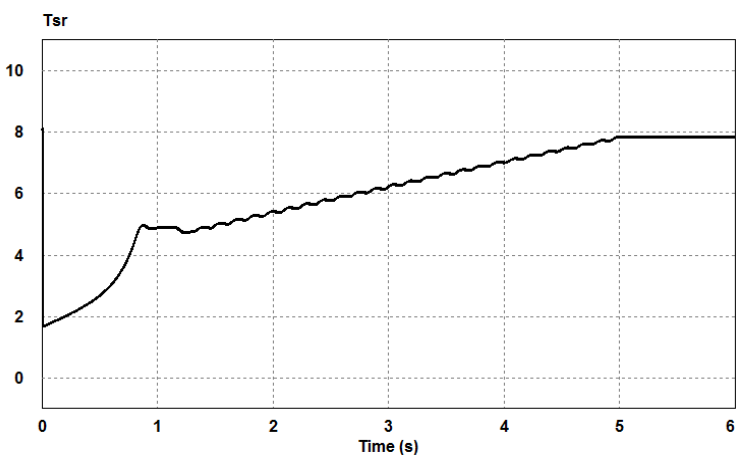

그림 12 주속비 $\operatorname{Tsr}(\lambda)$

Fig. 12 Tip speed ratio

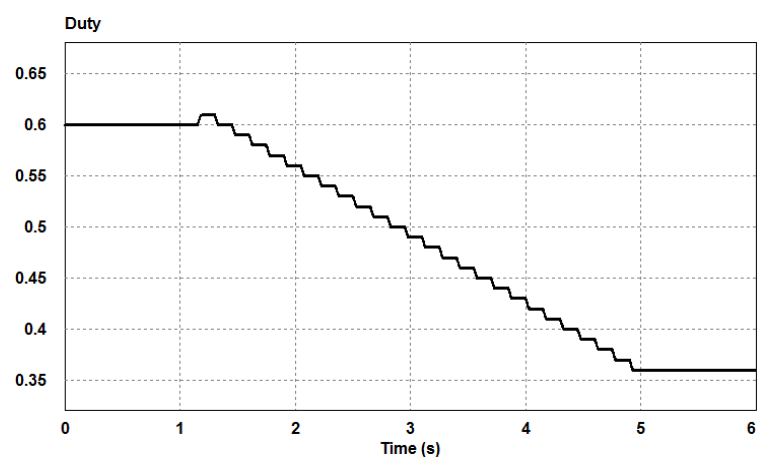

그림 $13 \mathrm{SMR}$ 의 듀티비

Fig. 13 Duty ratio of the SMR

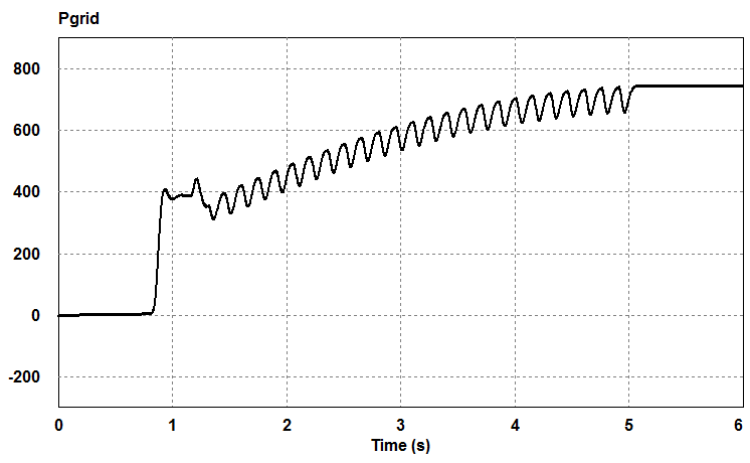

그림 14 인버터 출력전력

Fig. 14 Output power of the inverter 
그림 13은 SMR회로에서 MPPT제어를 수행하여 최대의 전력을 낼 수 있는 듀티값으로 추종하는 것을 볼 수 있다. 출력 전력은 그림 14 에 보이는 바와 같고 최대의 전력을 내 고 있음을 확인할 수 있다.

인버터 제어에 의하여 DC-link 전압은 300[V]로 정전압 제어가 되는 것을 그림 15 에서 확인할 수 있고 계통에 전력 을 최대로 보내기 위한 전압 전류의 위상이 동일함을 그림 16 을 통하여 확인할 수 있다.

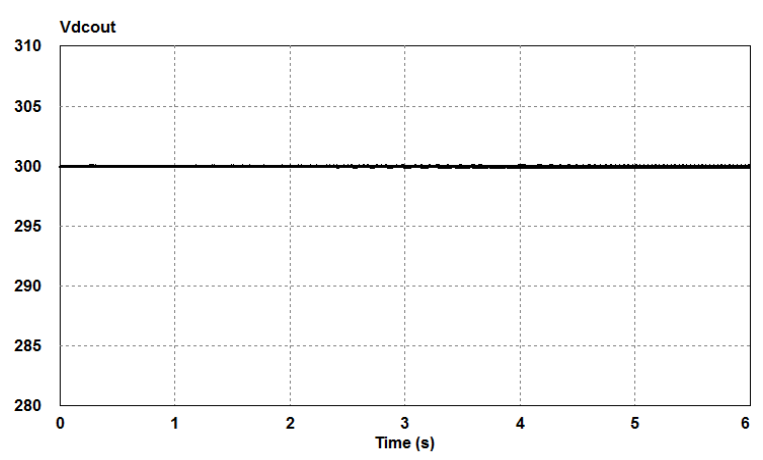

그림 $15 \mathrm{DC}$-link 전압

Fig. 15 Voltage of the DC-link

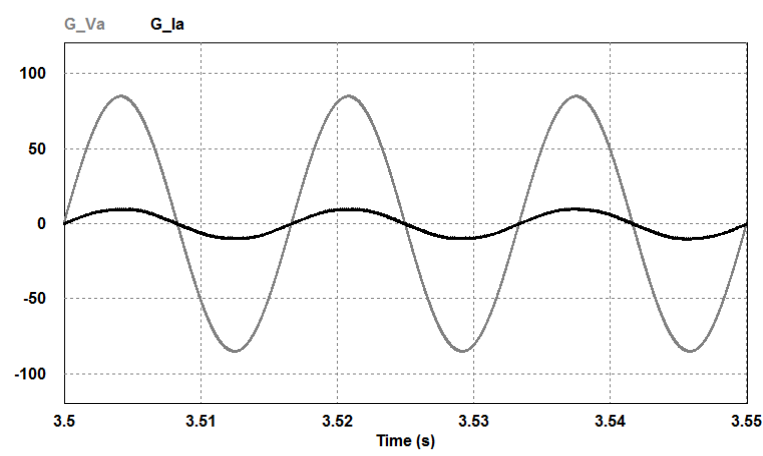

그림 16 계통 상전압 및 상전류 파형

Fig. 16 Grid phase voltage and current waveforms

\section{7 실험 결과}

전체시스템은 DSP28335를 이용하여 제어하였고 DSP의 Digital to analog converting(DAC) 기능을 사용하여 그림 17 의 변수들을 관찰하였다. 그림 17 에서 오른쪽 면에서 위 에서부터 순서대로 듀티, 효율계수 $\mathrm{Cp}$, 주속비 Tsr 및 계통 전력을 나타내고 있다. $\mathrm{DA}$ 의 스케일링에 의하여 각 변수가 표시하는 전압값은 실제값으로 환산하여야 한다. 그 환산 값은 표 2에 나타내었다.

\section{표 $2 \mathrm{DA}$ 값과 실제 환산값}

Table 2 DA value and the real value

\begin{tabular}{|l|l|l|}
\cline { 2 - 3 } \multicolumn{1}{c|}{} & $\mathrm{DA}$ 출력값 & 실제환산값 \\
\hline $\mathrm{Cp}$ & $0 \sim 10 \mathrm{~V}$ & $0 \sim 0.5$ \\
\hline $\mathrm{Tsr}$ & $0 \sim 10 \mathrm{~V}$ & $0 \sim 15$ \\
\hline Duty & $0 \sim 10 \mathrm{~V}$ & $0 \sim 1$ \\
\hline Pgrid & $0 \sim 10 \mathrm{~V}$ & $0 \sim 1000 \mathrm{~W}$ \\
\hline
\end{tabular}

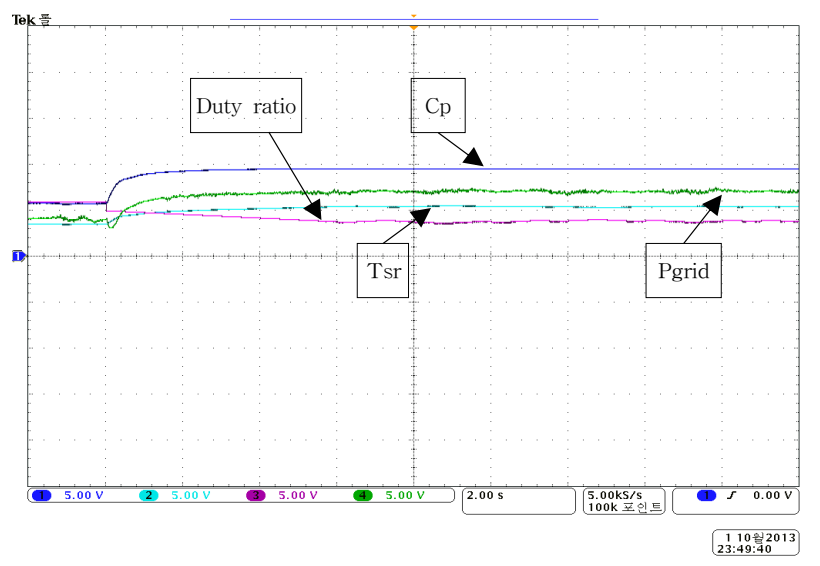

그림 17 듀티비 $\mathrm{Cp}, \mathrm{Tsr}$ 및 계통전력

Fig. 17 Duty ratio, Cp, Tsr and Power of the grid

풍속 $10[\mathrm{~m} / \mathrm{s}]$ 의 조건에서 실험을 진행하였다. 표 2 와 결 합하여 보면 그림 17에서 알 수 있다시피 듀티값은 최대의 전력을 내는 듀티값으로 추종하고 있고 효율계수인 $\mathrm{Cp}$ 는 0.48 인 최대의 값을 추종하고 있다. 마찬가지로 주속비도 8 인 값을 추종하고 있는 것을 확인할 수 있다. 이때 블레이 드 출력전력은 $1.2[\mathrm{~kW}]$ 이고 발전기의 출력전력은 $810[\mathrm{~W}]$ 정 도로 나오고 계통으로 전달되는 전력값은 그림 17에서 700[W]정도로 확인이 되었다.

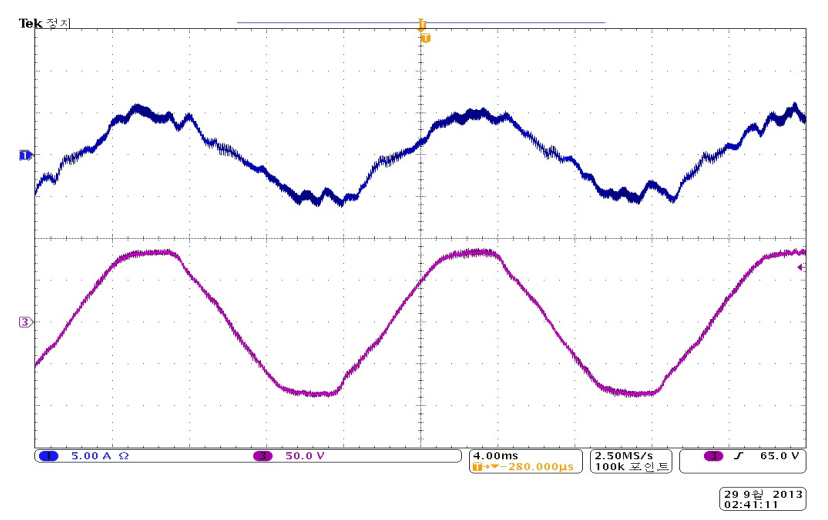

그림 18 계통 전류(상)와 계통전압(하) 파형

Fig. 18 Grid current and voltage waveforms

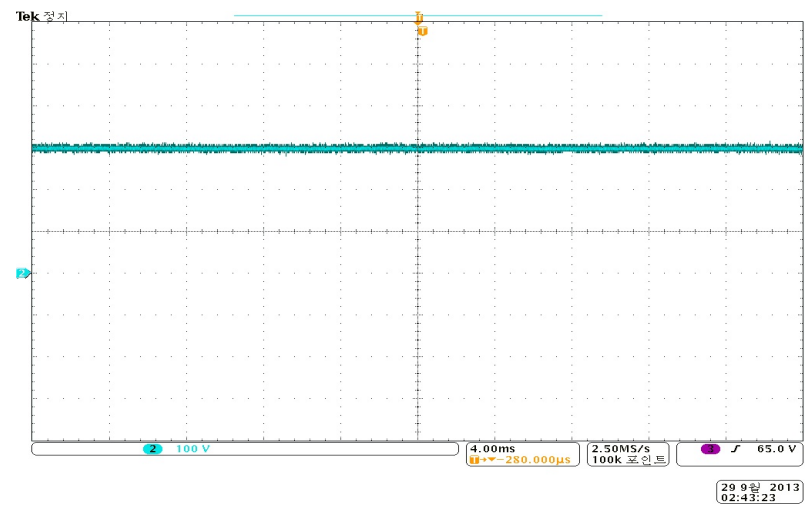

그림 19 DC-link 전압

Fig. 19 Voltage of the DC-link 
그림 18 은 계통전류와 전압 파형을 보여주고 있고 각각 대략 3.54[Arms], 60[Vrms]로 확인이 되었다. 블레이드에서 생성된 전력은 계통으로 흘러나감에 따라 동일 위상을 유지 하고 있음을 보여주고 있다. 인버터제어 의하여 DC-link정 전압 제어를 하고 있음을 그림 19에서 확인할 수 있다.

\section{3. 결 론}

$\mathrm{SMR}$ 회로와 센서리스 $\mathrm{MPPT}$ 를 결합한 풍력발전시스템 을 시뮬레이션을 통하여 가능성을 확인하였고 실험을 통하 여 검증을 하였다. 제안한 시스템은 기존의 풍력발전시스템 보다 소형으로 및 경량으로 만들 수 있고 제어가 간단하다. 그리고 수동소자의 제거로 단가를 줄일 수 있고 센서를 사 용하지 않아 센서의 유지 보수 등에 들어가는 비용을 절감 할 수 있다. 또한 최대의 전력을 낼 수 있는 추종제어가 가 능하여 발전기의 효율적인 면에서도 이득을 볼 수 있어서 소형 풍력발전시스템에 매우 적합한 시스템이라 할 수 있 다.

\section{감사의 글}

본 논문은 인하대학교 지원에 의해 수행되었습니다.

\section{References}

[1] C.A. Hernandez-Aramburo, T.C. Green, and N. Mugniot, "Fuel consumption minimization of a microgrid”, IEEE Trans on Industry Applications, Vol. 41, No. 3, pp.673-681, May-June, 2005

[2] Hye-su Shin, Chengde Xu, Joon-Min Lee, Jae-Du La and Young-Seok Kim, "MPPT control technique for a PMSG wind generation system by the estimation of the wind speed", ICEMS, Oct.2012

[3] R.Esmaili, L. $\mathrm{Xu}$ and D.K.Nichols, "A New Control Method of Permanent Magnet Generator for Maximum Power Tracking in Wind Turbine Application", Power Engineering Society General Meeting, Vol.3, Jun.2005

[4] D.M. Whaley, W.L Soong and N. Ertugrul, "Investigation of Switched-mode Rectifier for Control of Small-scale Wind Turbines", Proceedings of IEEE Industry Applications Society Annual Meeting, Vol.4, pp.2849-2856, 2005

[5] M. Chinchilla, S. Arnaltes, J.C.Burgos, "Control of Permanent Magnet Generators Applied to Variable-Speed Wind-Energy Systems Connected to the Grid”, IEEE Transactions on Energy Conversion, Vol.21, No.1, 2006.3

[6] E. Koutroulis, and K. Kalaitzakis, "Design of a Maximum Power Tracking System for Wind Energy Conversion Applications", IEEE Transactions on Industrial Electronics, Vol.53, No.2, pp.486-494, 2006.4
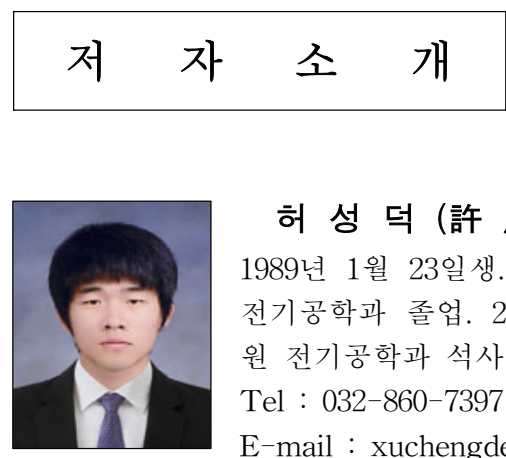

\section{허 성 덕 (許 成 德)}

1989년 1월 23일생. 2012년 인하대 공대 전기공학과 졸업. 2012년 현재 동 대학 원 전기공학과 석사 과정

Tel : 032-860-7397

E-mail : xuchengde7@hotmail.com

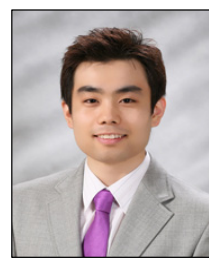

\section{이 준 민 (李 俊 旼)}

1982년 6월 16일생. 2009년 인하대 공대 전기공학과 졸업. 2011년 동 대학원 전기 공학과 졸업(석사). 2011년 2012년 LS 산전 근무. 2013년 현재 인하대 공대 전 기공학과 박사 과정

Tel : 032-860-7397

E-mail : wnsalsdldi0@naver.com

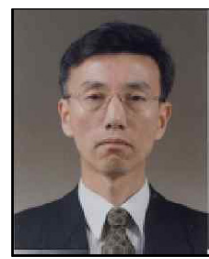

\section{김 영 석 (金 榮 石)}

1951년 6월 11일생. 1977년 인하대 전기 공학과 졸업. 1987년 일본 나고야대 대학 원 전기공학과 졸업(공박). 1987년 1989 년 전기연구원 전력전자연구실장. 1989년 현재 인하대 전기공학과 교수

Tel : 032-860-7397

Fax : 032-863-5822

E-mail : youngsk@inha.ac.kr 